\title{
Fifty years of tsetse control in Tanzania: challenges and prospects for the future
}

IMNA I. MALELE

Tsetse and Trypanosomiasis Research Institute, P. O. Box 1026 Tanga, Tanzania

Email: malelezi@yahoo.com

\begin{abstract}
Tsetse flies are the vectors of trypanosomes, the causative organisms of trypanosomiasis, nagana, in animals and sleeping sickness in man. In Tanzania, tsetse transmitted trypanosomiasis is one of the most important disease affecting both animals and humans. About $40 \%$ of land suitable for grazing and areas with high agricultural potential are currently tsetse infested. It is estimated that about 4.4 million livestock and 4 million people are at risk of contracting tsetse borne trypanosomiasis. African animal trypanosomiasis (AAT) causes loss in animals due to mortality and reduced milk yield, which is estimated at US\$ 7.98 million annually. Even after 50 years of independence, Human African Trypanosomiasis (HAT) or Sleeping Sickness is still one of the major public health problems with about 300 cases being reported annually. Tsetse control has been sporadic and uncoordinated hence no tangible results have been accrued since independence despite the fact that technologies which have facilitated tsetse control in other places are available. Fifty years of independence have seen shrinkage of tsetse belt to $43 \%$ in 16 surveyed regions. Opportunities for future are wide open if tsetse control will involve all stakeholders, who are directly or indirectly affected by the tsetse problem; if tsetse and trypanosomiasis eradication will adopt an area wide and participatory approach with emphasis on environmentally and user friendly techniques for expanded livestock sector; improved food security and livelihood in affected communities, for achievement of the millennium development goals.
\end{abstract}

Keywords: tsetse, trypanosomiasis, distribution, traps, targets, Tanzania

\section{Introduction}

Tsetse flies belong to the genus Glossina, family Glossinidae, within the order Diptera; and are found between $14^{\circ}$ North and $29^{\circ}$ South in Africa (Buxton, 1955). Between these latitude limits, the species of Glossina are widely but not universally distributed, though one or more occur wherever the environment is suitable. Temperature plays an important role in determining the limit of tsetse distribution; normally temperatures below $7{ }^{\circ} \mathrm{C}$ above $39^{\circ} \mathrm{C}$ are taken as critical preventing the development of the puparia (Žd'árek \& Denlinger, 1993). Species that are included in this genus fall into three well defined groups referred to as the Fusca group which mainly consist of species which inhabit forest vegetations; the Palpalis group of which most of the members are the riverine species found on the western part of Africa; and lastly the Morsitans group; the savannah tsetse flies, which are found in large areas of southern and Eastern Africa (Buxton, 1955; Jordan, 1986).

Tsetse flies are the vectors of trypanosomes, the causative organisms of trypanosomiasis, nagana, in animals and sleeping sickness in man. Tsetse flies become infected with trypanosomes by feeding on an infected host. Many of the wild mammals in tsetse infested areas are infected with trypanosomes without suffering from disease symptoms. These animals act as reservoirs of trypanosomes ensuring that some tsetse always becomes infected.

\section{Economic importance of tsetse}

The trypanosomes undergo development in the fly and are transmitted when an infected fly takes a blood meal on an uninfected host. If the uninfected host is not trypanotolerant (e.g. man and some domestic animals) then disease usually results. The disease causes death of countless domestic animals especially cattle, and therefore tsetse infested areas are deprived of meat, milk and the use of animals for draught purposes (Jordan, 1985). Sometimes farmers are forced to keep their animals alive by the use of drugs like isometamidium chlroide and diminazene 
aceturate. Despite the free market that ensures easy availability of trypanocidal drugs still there is frequent under dosing of animals with the subsequent development of resistance to the commonly used drugs (Mbwambo et al., 1988). Tsetse infestation renders most of fertile areas unexploited. These areas could be used for farming and thus would contribute to a nation's economy. Overgrazing and degradation of tsetse free areas is rather common as most of the cattle are confined to uninfected areas (Malele et al., 2011).

There are several types of trypanosomes pathogenic to man and domestic animals that are transmitted by tsetse. These include Trypanosoma congolense, T. brucei brucei, T. b. gambiense, T. b. rhodesiense and T. vivax. Others are T. simiae Tsavo, T. godfreyi. The rate of infection of tsetse flies by trypanosomes varies from species to species and from one place to another (Jordan, 1974, 1986). For example the infection rate in the Fusca and Palpalis groups is usually much lower than in the Morsitans group. The rate of infection depends on a number of factors (Jordan, 1986; Leak, 1999). These include: (i) Endogenous factors - are those associated with the fly such as age at first infective feed, sex, intra and inter species genetic differences, fly behavior, host preferences, physiological and biochemical state, concurrent infection by viruses, bacteria and fungi; (ii) Ecological factors - such as climate, availability of infected wild and domestic animals for subsequent feeding; and (iii) Parasite and host factors - which include parasite numbers available to the fly, type of parasite, its infectivity to the fly, immune status of the host species, host breed, host behaviors' and its attractiveness to the fly.

The human disease is another setback which results from the presence of tsetse. The number of new cases reported in 2009 has dropped below 10,000 for the first time in 50 years (WHO, 2010). This is a decrease of $63 \%$ since 2000 . In 2009 , only two countries reported more than 1,000 new cases, namely Republic of Central Africa and DRC representing, respectively, $11 \%$ and $73 \%$ of the total cases reported (Simarro et al. 2011). Recent estimates indicate that over 60 million people living in some 250 locations are at risk of contracting the disease, and there were under 10,000 cases reported in 2009 (WHO, 2010) which represents a huge decrease from the estimated 300,000 new cases in 1998 (WHO, 1998). In addition, the presence of tsetse causes human beings to abandon their settlements, such depopulation and cessation of farming activities normally leads to thicker growth of bushes and the consequent extension of suitable habitat for Glossina (Reid et al., 2000).

\section{Historical and current tsetse distribution in Tanzania}

According to the distribution map produced in 1977 by Ford \& Katondo (1977) it shows that twothirds of the total land of Tanzania is infested by 10 species and sub species of Glossina. The species include both the Savannah (Morsitans): G. morsitans morsitans, G. m. centralis Mochado 1970, G. swynnertoni, G. pallidipes and G. austeni; Forest species (Fusca): G. longipennis, G. brevipalpis and G. fuscipleuris, and to a lesser extent the Palpalis (Nermohina): G. fuscipes, G. $f$. martini Zumpt 1933, which are restricted towards Lakes Victoria and Tanganyika respectively (Ford \& Katondo, 1977). One third of the total land was protected land in the form of national parks, game and forest reserves.

Until now the available distribution map used, is the one produced by Ford \& Katondo (1977). Recent efforts to come up with new distribution map indicate that the area which is tsetse infested is estimated to be $15.5 \%$, and for an area with high to low risk tsetse infested area is $27 \%$ and non risk tsetse area is $57.4 \%$. This brings an overall tsetse infested risk area of about $43 \%$ (MLFD, 2011) out of the total 16 regions surveyed. Studies conducted from 2005- 2007 (Malele et al., 2011) also showed that tsetse distribution has been altered as a result of several reasons which include changes in land use, which include human settlement and associated activities, infrastructure development and land reform policies. These have significantly contributed to the new tsetse distribution limit. Movement and settlement of huge stocks of insecticide baited livestock in once tsetse infested areas has significantly altered the ecology of favored tsetse 
habitats and their hosts leading to the disappearance of tsetse breeding sites and tsetse species. Human population increase in formally tsetse infested areas has also contributed to the disappearance of tsetse. The most affected region was Rukwa due to increased farming following the settlement of mixed farmers from Tabora and Shinyanga in search of land, pasture

and water for their cattle (Kilemwa, 1999) than those going out (www.tanzania.go.tz/census/census/htm). As a result there is an increase in demand for fuel (fire wood), construction materials, infrastructures etc. The pastoralists who have settled in Rukwa have also embraced the use of animal traction for farming. Clearing of large areas which were tsetse infested for farming (Kilemwa, 1999) and this have destroyed favored tsetse breeding and resting sites. It was found in the study that tsetse confinement to protected areas, which include national parks, game and forest reserves. Land reform policy, increased investment and mining activities are likely to see a continued shrink of the former tsetse distribution limit and continued restriction of tsetse to protected and reserved areas which are spared from human activities (Malele et al., 2011).

\section{Tsetse control methods}

\section{Tsetse control before independence}

Tanzania is one of the countries that are very much affected by tsetse and thus tsetse borne diseases for both human beings and domestic animals. Tsetse fly control in this country was initiated by colonial rule and the methods which have been deployed since colonial rule and soon after independence to date are briefly explained below.

Clearing of vegetations: Vegetation serve as habitat for different species of tsetse when the habitat is removed, tsetse flies also disappear. Clearance of vegetation was applied either by total or by removing only vegetation that was vital to the support of tsetse flies (Hocking et al., 1963; Jordan, 1986). However this method coupled with clearance of large areas for farming left the areas which had widely practiced this methodology (Shinyanga and Mwanza) with a permanent effect turning the areas into drought without much rainfall. The method is no longer used from the environmental point of view, as cutting trees haphazardly leads to deforestation and soil erosion (Jordan, 1986).

Destruction of hosts: Tsetse flies feed on wild animals which act as a reservoir for the trypanosomes infective to domestic animals and man. Removal of wild animals leads to the decline in fly infestation and reduction in the availability of infected feeds, and ultimately control of trypanosomiasis. Control of tsetse by killing wild animals was widely used in East Africa (Tanzania inclusive) and Central Africa (Hocking et al., 1963; Jordan, 1986), but nowadays the method is unacceptable again on environmental grounds.

\section{Commonly used methods after independence}

Chemical methods: Control of tsetse by chemicals is the quickest way of reducing fly population; however refinement of droplets is important to minimize chemical loss by being blown away without reaching the targeted organism. Insecticides use is either by ground spraying or aerial spraying. The method was extensively used in northern Tanzania especially in Arusha region against vectors of sleeping sickness in areas of Babati (Tarimo et al.,1971a,b; Tarimo, 1974) The insecticide were either formulated as residual or non residuals. The insect acquires a lethal dose through tarsal contact, in the case of residuals like endosulfan and DDT, or through droplets impinging on the body surface in the case of non - residuals like the pyrethroid compounds. The chemicals were either applied from the ground by selective application to the known fly resting sites, or by aerial spraying (Hocking et al., 1963; Jordan, 1986).

Although insecticides are at present used by many countries for tsetse control and have been very successful in certain parts they still have some drawbacks especially with re-invasion if barriers are not instituted (Muzari \& Hargrove, 1996). So systemic approach from one area to the 
other is important to avoid re-invasion; and if control is on tsetse populations which extends to other countries, then joint efforts between countries is the only way to prevent re-invasion from uncontrolled country.

The Sterile Insect Technique (SIT): SIT is one of the biological tsetse control method. It involves sustained and systematic releases of sterile male insects among the indigenous target population. The mating of sterile males with fertile female insects results in infertility in the female throughout her remaining life span although recently it has been proved otherwise in some tsetse species like G. f. fuscipes (Bonomi et al., 2011) where there is polyandry. Flies need to be reared in rearing laboratories for surplus males which are gamma sterilized for release while females are left in the colony for breeding. Continuous release of sterile males in quantities and over time of the target species reduces its reproductive capacity and thus the reproductive population. Released males need to outnumber the wild fertile males for the wild population to collapse. The technology works best when the target population in an area is low, hence a need for other technologies to be used prior the application of SIT in order to reduce the wild populations.

The first SIT program was conducted in Tanzania (1972 - 1979) against G. m. morsitans and achieved about $83 \%$ reduction of G. m, morsitans at Mkwaja ranch (Williamson et al., 1983); to date the ratio of G. m. morsitans is always low compared to other species especially G. pallidipes which was not targeted by the program. However lack of effective barrier saw inversion of other species from uncontrolled areas and washed away all the achievement against the vector. In 1994 - 1997, the country saw a successful control of G. austeni in Zanzibar Island of Unguja (Msangi et al., 2000) and the island is free from cyclically transmitted trypanosomiasis.

Traps and targets: Tsetse traps and targets (insecticide-impregnated screens) function by attracting the flies to a device that collects and/or kills them. Traps and targets, hence trapping techniques, have been developed to mimic the fly's perception of the vertebrate hosts. They are made of blue and black cloth in a shape that attracts the flies and then funnels them upwards into a netting trap. The colours are used to exploit tsetse wavelength whereby they are attracted by blue colour and elicited to land on black colour (Green, 1994). Traps can be used for entomological surveillance, and also for control. Targets are simpler than traps, but both (traps and targets) can be impregnated with biodegradable insecticides in order to kill any flies that alight on them. Various designs of trap and target have been developed for use against particular target species in particular environments. They differ in cost and maintenance requirements, and are not always effective for all species. The effectiveness of traps and targets as control tools depends on their rate of removal of flies from the existing population; however they are important component for estimating the control and prevent trypanosomiasis epidemics. Traps and targets are important as suppression tool before other application by other technique like SIT or sequential aerial technique (SAT) (Kgori et al. 2006) are applied against the vectors. Traps and targets can be used in combination with live baits to speed up suppression of the vector before elimination is achieved.

For tsetse control, a simpler and cheaper device involves a suspended screen of blue and black cloth (often known as a tsetse target) impregnated with a biodegradable pyrethroid insecticide such as deltamethrin. Flies are attracted by the blue segments and land on the black segment, quickly succumbing to the insecticide. The effectiveness of traps and targets is usually enhanced by addition of appropriate odours like octanol and acetone.

From the early 1980's the use of baits (visual and olfactory) for tsetse control has been used in many tsetse infested countries like Kenya, Zimbabwe etc. Traps of different shapes and colour have been tested for several tsetse species and proved very effective in catching the tsetse flies (Muangirwa et al., 1994a, b). Their efficiency is enhanced through use of odour attractants and this applies to insecticide-treated traps and targets (Screens) as well. In Tanzania, traps and targets have been in use in the country since 1975 though in small scale and sporadic programs. These were carried out in Mkwaja (Gao et al., 1990), northern and central Tanzania 
(Muangirwa et al., 1994c) and Kasulu (Daffa et al., 2003). Compared with ground or aerial spraying of insecticides, the bait methods have many advantages first the technique is environmentally benign and affordable by the communities. However, bait technology has some drawbacks of being too slow to achieve results and being unable to eradicate some populations.

The bait technology: The bait technology can also be used on live animals or moving objects like sprayed vehicles. live bait technique involves treating cattle with appropriate insecticide formulations, usually by means of cattle dips, or as pour-on, spot-on, or spray-on veterinary formulations. These are highly effective against tsetse, and have the additional advantage of controlling other flies and cattle ticks and have been in use since early $1990 \mathrm{~s}$ in Mkwaja, Mzeri and Kagera ranches. Deltamethrin treated cattle were used to control and reduce the tsetse challenges at Mkwaja (Fox et al., 1991) and Kagera (Hargrove et al., 2003) ranches. Use of baited animals as Insecticide Treated Cattle (ITC) is currently a common practice which is easily adopted by farmers to control tsetse.

\section{Challenges of tsetse control}

Successful tsetse control need to be supplemented with research and capacity building both in terms of infrastructure and manpower, control of parasites in both host animals especially domestic animals and infected human beings. Tsetse transmitted trypanosomiasis is one of the most important disease affecting both animals and humans. About $40 \%$ of land suitable for grazing is currently tsetse infested. Areas with high agricultural potential which include Arusha, Manyara, Kilimanjaro, Rukwa, Katavi, Kagera, Mara, Tabora, Tanga and Kigoma regions are highly affected by tsetse and trypanosomiasis.

It is estimated that about 4.4 million livestock and 4 million people are at risk of contracting tsetse borne trypanosomiasis. African animal trypanosomiasis (AAT) causes loss in animals due to mortality and reduced milk yield, which is estimated at US\$ 7.98 million annually (MOAC 1995). However, these losses do not include other production parameters and costs of tsetse control. Besides, chronic trypanosomiasis is also responsible for huge economic losses in terms of low body weight gains, high sterility and/or abortions and predisposition of affected animals to other infections. AAT affects availability and efficient utilization of draught power, which has lead to low acreage on agricultural systems. Cattle, small ruminants and donkeys cannot be kept under trypanosomiasis challenge without using large quantities of trypanocidal drugs. Furthermore, there have been reports of widespread resistance to such drugs in Tanzania since 1988 (Mbwambo et al., 1988). The disease is a threat to food security in Tanzania. Reclaiming land from tsetse will enhance livestock productivity and use of livestock tracking power which could in turn lead to more and beneficial agricultural output for improved food security and contribute to healthier communities in tsetse infested areas and the nation at large.

Even after 50 years of independence, Human African Trypanosomiasis (HAT) or Sleeping Sickness is still one of the major public health problems. Sleeping sickness seriously affects the workforce and cost households in terms of treatment and time spent in taking care of sick members of the family. Convalescing individuals take long before re-engaging in substantial productive work (Matemba et al., 2010). Number of HAT cases being reported annually has decreased to about 300 cases per year ( $\mathrm{MoH}, 2005 \mathrm{a})$. However, this data doesn't reflect the actual situation due to under reporting for being a neglected problem of the rural poor. It is also often confused with HIV AIDS, malaria and TB (Malele et al., 2006). Studies by Kibona et al., (2006) indicated that there was some reduction in susceptibility of T. brucei rhodesiense isolates to drugs commonly used against HAT which strongly indicated that drug resistance may be emerging in north-western Tanzania. Tsetse and thus tsetse borne disease for human beings is also a threat to tourism sector and environment conservation (Jelinek et al., 2002; Kaare et al.,

2007). Deliberate efforts and appropriate strategies that are sustainable; user and 
environmentally friendly are seriously needed to avert tsetse and tsetse borne diseases debilitating effects.

Technologies for tsetse control are available (Msangi et al., 2000; Hagrove et al., 2003; Kgori et al., 2006). However, they have not been well or fully embraced in the control of tsetse due to resource constraint both in terms of man power and funds to implement control programs. In many areas especially in Local Government setting, staff to deal with tsetse control is not available or because of other pressing issues, tsetse personnel are assigned other activities not related to tsetse control. Another challenge facing tsetse control in Tanzania is due to the fact that hot spots for tsetse breeding are currently confined to protected areas in the form of game reserves, national parks etc such that even if peripheral areas are controlled, still there will be re-invasion from protected areas. Hence effective control can only be achieved by joint efforts between authorities responsible for protected areas like Tanzania National Parks (TANAPA), the Wildlife Division in the Ministry of Natural resources and Local governments. It is only through jointly and coordinated efforts against tsetse that the vector will be eliminate from this county.

\section{Prospect for the future}

\section{Shrinking tsetse distribution limit}

Tsetse control have evolved over the years, the much thought and believed that tsetse are for keeping Africa green and that they are there to protect natural resources like game and national parks is no longer valid. Due to recent epidemic of HAT among tourists and staff in the parks, there has been a shift in the control strategies such that more and more stakeholders have joined war against tsetse. In recent years, a number of national parks in the country have initiated tsetse control first to reduce nuisance caused by tsetse to tourists and staff, but also to reduce the risks of contracting HAT (Mlengeya et al., 2002). The technologies mostly adopted in game reserves involve the use of traps, stationery targets/screens and mobile baits (vehicles). Data available indicate that TANAPA has deployed more that 20,000 screens/targets and sprayed more than 80,000 vehicles between 2007 and 2010 (Muse, 2011). Also fly pickets are used to spray vehicles at entry and exit points of most national parks in order to control tsetse.

\section{Pan African Tsetse and Trypanosomiasis Eradication Campaign (PATTEC) Initiative}

There is positive prospect for the future in terms of tsetse control. First there is a PATTEC declaration number AGH/Dec. 156 (XXXVI) of the $36^{\text {th }}$ Summit of AU Heads of State and Government, made in Lome, Togo, in July 2000 of which Tanzania as a member state agreed to coordinate efforts and ensure the continent of Africa is free from tsetse and trypanosomiasis using an Area-Wide and Sustainable Approach. The systematic and phased area wide approach against the vector is advocated against tsetse in a "roll a carpet model", where natural barriers can be used as a starting point to eradicate tsetse from one area to the other (Kabayo, 2002). However plans need to be in place to make use of tsetse free areas so that to eliminate the risks of re-infestation and or re-inversion. The trans-boundary nature of tsetse belts need to be taken in account so that countries sharing the same tsetse belts are required to join hand and target tsetse control form both angles in order to eliminate the likelihood of re-infestation from one country which has not controlled the target tsetse belt. Also tsetse eradication is realized much faster when different technologies are integrated in the control and eradication.

\section{Involvement of all stakeholders}

Tsetse control needs to involve all stakeholders, and in Tanzania the following are key stakeholders that need to take part in tsetse control whether directly and indirectly affected be by the problem. These include Ministries responsible for Livestock, Agriculture, Natural resources, Local Government, Gender and Children, Lands and Planning, Education, Research Institutes, private sectors and community based organizations as well as non Governmental 
organizations. These have different roles and all need to play an active role in tsetse control. Their roles could be through policy formulations, funding, Harmonization and regulation and enforcement of policy and laws related to implementation of vector control plans; coordination of tsetse control at ecological interface areas, promotion and involvement of all gender groups because tsetse effects cuts across gender groups. Efforts need to be done to sensitize the community at all levels, mobilize funds for research and capacity building both in terms of capacity building (manpower and infrastructures) (MoH, 2004, 2005b; MLDF, 2011).

\section{Environmentally friendly approach}

Tsetse control should also aim not only at eradicating the vector, but also conservation of agrobiological diversity and ecosystems in tsetse controlled areas. Tsetse control methods have been refined such that their impact to environment has been minimized. The use of environmentally friendly technique is important in order to conserve the environment form pollution and toxicity of non targeted organisms (TDR, 2004). Hence methodology chosen should take into consideration their effects on the environment and their cost benefit. Environmental impact assessment and monitoring need to be conducted before and after implementation of tsetse control programmes.

\section{Participatory Tsetse Approaches}

All relevant stakeholders such as central and local government, communities, development partners and the private sector need to be involved in tsetse control and eradications. About 80 $\%$ of livestock keepers are also crop farmers while $20 \%$ are pastoralists. These should not be left behind in tsetse control through participatory approach and this group can significantly contribute towards tsetse control by ITC. Recently it has been reported that the deployment of ITC is one of the most cost effective means of controlling tsetse especially if the ITC are evenly distributed in a tsetse infested area (MoH, 2004, 2005b; MLDF, 2011; Torr \& Vale, 2011).

\section{Conclusion}

Control tools for tsetse eradication has been tested, perfected and are currently available for use against the vector. The tsetse distribution limit has changed in favour of eradicating tsetse. The once continuous fly belt has fragmented creating the tsetse belt into more island-like areas. This facilitates tsetse eradication using a "roll over carpet model" where one tsetse infested island could be reclaimed. Tsetse control in the coming years need to use an Area Wide approach as advocated by PATTEC, be multi-sectoral for sustainable control and achievable tangible control benefits which include proper land use plan of reclaimed areas from tsetse infestation to avoid land degradation by irrational use like overstocking of animals which could lead to land degradation. With the onset of trypanocidal resistance for both AAT and HAT, the only permanent solution to avoid this is to get rid of tsetse in order to break the transmission cycle. Political resolve through PATTEC initiative to control and eradicate tsetse is also one of the added advantage for achieving the goal of eliminating tsetse. Hence deliberate efforts and resolve is need at all levels and among all stakeholders to join hand and resources to eliminate tsetse. Tsetse flies need to be eradicated so as to improve the livelihood of communities in tsetse infested areas, improve food security in the country and contribute towards the achievement of Millennium Development Goals.

\section{Acknowledgements}

The information included in this review has been collected from different stakeholders. I wish to acknowledge the PATTEC Coordinator at the Ministry of Livestock and Fisheries Development 
and the HAT control focal person at the Ministry of Health and Social Welfare for the information provided.

\section{References}

Bonomi, A., Bassetti, F., Gabrieli, P., Beadell, J., Falchetto, M., Scolari, F., Gomulski, L. M., Regazzini,E., Ouma, J. O., Caccone, A., Okedi, L.M., Attardo, G. M., Guglielmino, C. R., Aksoy, S. \& Malacrida, A. R. (2011) Polyandry Is a Common Event in Wild Populations of the Tsetse Fly Glossina fuscipes fuscipes and May Impact Population Reduction Measures. PLoS Neglected Tropical Diseases 5(6): e1190.

Buxton, P.A (1955) The Natural History of tsetse flies, University press, Glassgow.

Daffa, J., Njau, W. \& Mwambembe, E.H., (2003) Involvement of the community in tsetse and trypanosomosis control activities: Tanzania experience. $27^{\text {th }}$ ISCTRC meeting, $29^{\text {th }}$ Sept. $3^{\text {rd }}$ Oct., 2003, Pretoria RSA

Ford, J. \& Katondo, K.M. (1977) Maps of tsetse flies (Glossina) distribution in Africa, 1973, according to sub generic groups on scale of 1: 5,000,000 (plus a set of 9 maps in colour). Bulletin of Animal Health and Production in Africa 2, 187-193.

Fox, R.G.R., Mbando, S.O. \& Wilson, A. (1991) The effect on herd health and productivity of controlling tsetse \& Trypanosomosis by application of deltamethrin to cattle. $21^{\text {st }}$ Meeting of I.S.C.T.R.C., Cote d'Ivoire.

Gao, M.K., Mramba, F., Bakuli, B. \& Chakale, B. (1990) Efficacy of Decatix (deltamethrin 5\%) cattle dips on tsetse flies at Mkwaja Ranch, Tanga Region. Tanzania Ministry of Agriculture and Livestock Development. Research and Training Newsletter 5, 3-5.

Green, C.H. (1994) Bait methods for tsetse fly control. Advances in Parasitology 3,229-291.

Hargrove, J.W., Torr, S.J. \& Kindness, H.M. (2003) Insecticide treated cattle against tsetse (Diptera: Glossinidae); what governs success? Bulletin of Entomological Research 93, 203 217.

Hocking, K.S,. Lamerton, J.F. \& Lewis, E.A. (1963) Tsetse-Fly Control and Eradication. Bulletin of the World Health Organization 28, 811-823.

Jelinek, T., Bisoffi, Z., Bonazzi, L., van Thiel, P., Bronner, U. \& De Frey, A. (2002) Cluster of African trypanosomiasis in travelers to Tanzanian national parks. Emerging Infectious Diseases pp. 634-635.

Jordan, A.M. (1986) Trypanosomiasis Control and African Rural Development. Longman Inc., New York.

Jordan, A.M. (1974) Recent development in the ecology and methods of control tsetse flies (Glossina spp) (Diptera: Glossinidae) a review. Bulletin of Entomological Research 63, 361399.

Jordan, A.M. (1985) The vectors of African trypanosomiasis: Research towards non insecticidal methods of control. British Medical Bulletin 41, 181-186.

Kabayo, J.P. (2002) Aiming to eliminate tsetse from Africa. Trends Parasitology 18, 473-475.

Kibona, S.N, Matemba L, Kaboya, J.S. \& Lubega, G.W. (2006) Drug-resistance of Trypanosoma b. rhodesiense isolates from Tanzania. Tropical Medicine \& International Health 11, 144-155.

Kilemwa, A.M. (1999) Environmental impact of animal traction in Rukwa region, Tanzania. In: P. Starkey and Kaumbutho $P$ (eds). Meeting the challenges of animal traction. A resource book of the Animal Traction Network for Eastern and Southern Africa (ATNESA), Harare Zimbabwe, London, p. 326.

Kgori, P.M, Modo, S. \& Torr, S.J. (2006) The use of aerial spraying to eliminate tsetse from the Okavango Delta of Botswana. Acta Tropica 99, 184-199.

Leak, S.G.A (1999) Tsetse Biology and Ecology. Their Role in the Epidemiology and Control of Trypanosomosis. CAB International, Oxford, pp. 98-100. 
Malele, I., Nyingilili, H. \& Msangi, A. (2011) Factors defining the distribution limit of tsetse infestation and the implication for livestock sector in Tanzania. African Journal of Agricultural Research 6, 2341-2347.

Malele, I.I, Kibona, S.N, Matemba, L.E, Sahani, K., Swila, J., Mwalimu, C.D, Mayala,B.K., Msumary, C. \& Kalinga, R.B. (2006) Human African Trypanosomiasis and challenges to its control in Urambo, Kasulu and Kibondo districts, western Tanzania. Tanzania Health Research Bulletin 8, 80-85.

Matemba, L.E, Fe'vre, E.M, Kibona, S.N, Picozzi, K., Cleaveland, S., Shaw, A.P., Welburn, S.C. et al. (2010) Quantifying the Burden of Rhodesiense Sleeping Sickness in Urambo District, Tanzania. PLoS Neglected Tropical Diseases 4(11): e868.

Mbwambo, H.A, Mella, P.N. \& Lekaki, K.A. (1988) Berenil (diminazene aceturate)-resistant Trypanosoma congolense in cattle under natural tsetse challenge at Kibaha, Tanzania. Acta Tropica 45, 239-244.

MoH (2004) Multi-sectoral Policy Guidelines on Vector and Vector Borne. Ministry of Health, Dar es Salaam, Tanzania.

MoH (2005a) Five Years Strategic Plan for the Control of Vectors and Vector-borne Diseases. Ministry of Health, Dar es Salaam, Tanzania.

$\mathrm{MoH}$ (2005b) National Human African Trypanosomiasis (HAT) Elimination Programme Strategy. Ministry of Health, Dar es Salaam, Tanzania.

MLFD (2011) Tsetse and Trypanosomiasis Eradication Strategy in Tanzania. Ministry of Livestock and Fisheries Development, Dar es Salaam, Tanzania.

Muangirwa, C.J., Mattechi, H.T, Macha, P.S.M., Mbise, S.R., Sikay, M. \& Doriye, R. (1994a) Assessment of catches of tsetse flies (Glossina pallidipes, G. swynnertoni and G. morsitans centralis) in biconical traps baited with various odour attractants in northern and central Tanzania. TPRI Miscellaneous Report 1064, 13- 22.

Muangirwa, C.J, Mattechi, H.T, Macha, P.S.M, Sikay. M., Doriye, R. \& Mbise, S.R. (1994b) Assessment of catches of tsetse flies (Glossina pallidipes, Glossina swynnertoni and Glossina morsitans) in various traps in northern and central Tanzania. TPRI Miscellaneous Report 1064, $23-31$.

Muangirwa, C.J, Sikay, M., Mattechi, H.T. \& Doriye, R. (1994C) Residual effectiveness of insecticide (alphacypermethrin, SC) impregnated targets on population of tsetse flies (Glossina swynnertoni) in northern Tanzania. TPRI Miscellaneous Report 1064, 32-39.

Muse, E.A. (2011) The Role of TANAPA in Tsetse and Trypanosomiasis Control. Paper Presented at Tsetse and Trypanosomiasis Stakeholders' Meeting on $5^{\text {th }}$ December 2011 at Corridor Springs Hotel, Arusha.

Muzari, M.O. \& Hargrove, J.W. (1996) The design of target barriers for tsetse flies, Glossina spp. (Diptera: Glossinidae). Bulletin of Entomological Research 86, 579-583.

Mlengeya, T.D.K., Muangirwa, C., Mlengeya, M.M., Kimaro, E., Msangi, S. \& Sikay, M. (2002) Control of Sleeping Sickness in the Northern Parks of Tanzania. Proceedings of the Third Annual Scientific Conference of the Tanzania Wildlife Research Institute, Arusha, December 35, 2002. pp 274-282.

Msangi, A.R., Salehe, K.M, Kiwia, N.E, Malele, I.I., Musa, W.A., Mramba, F., Juma, K.G., Dyck, V.A., Vreysen, M.J.B., Parker, A.G., Feldmann, U., Zhu, Z-R. \& Pan, H. (2000) Success in Zanzibar: Eradication of Tsetse. In: Tan, K.H. (ed.) Area-wide management of fruit flies and other major insect pests. Penang, Penerbit Universiti Sains Malaysia, pp. 55-66.

Reid, R.S., Kruska, L.R.L., Deichmann, U., Thornton, P.K. \& Leak, S.G.A. (2000) Human population growth and the extinction of the tsetse fly. Agriculture, Ecosystems \& Environment 77, 227236.

Simarro, P.P., Diarra, A., Ruiz Postigo, J.A, Franco, J.R.\& Jannin, J.G. (2011) The Human African Trypanosomiasis Control and Surveillance Programme of the World Health Organization 2000-2009: The Way Forward. PLoS Neglected Tropical Diseases 5(2): e1007. 
Tarimo, C.S., Parker, J.D. \& Kahumbura, J.M. (1971a) Aircraft applications of insecticides in East Africa XX and XXI-. Pyrethrum Post 11,18-23.

Tarimo, C.S. (1974) The control of Glossina swynnertoni Aust. with synergized pyrethrum from the ground. Pyrethrum Post 12, 116-118.

Tarimo, C.S., Parker, J.D. \& Kahumbura, J.M. (1971b) Aircraft applications of insecticides in East Africa XX - The control of Glossina swynnertoni Aust. and G. pallidipes Aust. in savanna woodland with a pyrethrum/DDT mixture. Pyrethrum Post 11, 18-20.

Torr, S.J. \& Vale, G.A. (2011) Is the even distribution of insecticide-treated cattle essential for tsetse control? Modeling the impact of baits in heterogeneous environments. PLoS Neglected Tropical Diseases 5(10): e1360.

TDR/IDE/TRY/05.1 (2004) Strategic review of traps and targets for tsetse. apps.who.int/tdr/publications/...traps-targets-tsetse/.../tsetse_traps.pdf.

Williamson, D.L., Dame, D.A., Gates, D.B., Cobb, P.E., Bakuli, B. \& Warner, P.V. (1983) Integration of insect sterility and insecticides for control of Glossina morsitans morsitans Westwood (Diptera: Glossinidae) in Tanzania. V. The impact of sequential releases of sterilized tsetse flies. Bulletin of Entomological Research 73, 391-404.

WHO (2010) Human African trypanosomiasis: number of new cases drops to historically low level in $50 \quad$ years. Available: http://www.who.int/neglected_diseases/integrated_media/integrated_media_hat_june_2 010/en/index.html

WHO (1998) WHO Expert Committee on Control and Surveillance of African trypanosomiasis. World Health Organization, Technical Report Series, No.881.

Žd'árek, J. \& Denlinger, D.L. (1993) Metamorphosis behaviour and regulation in tsetse flies (Glossina spp.) (Diptera: Glossinidae): a review. Bulletin of Entomological Research 83, 447461. 